\title{
Effects of Cattle Integration on Non-Crop Vegetation and Parasitic Hymenoptera Diversity in Oil Palm Plantations in Central Kalimantan, Indonesia
}

\author{
Dani Aldinas ${ }^{1}$, Radhian Prabowo ${ }^{2}$, Damayanti Buchori ${ }^{1,3^{*}}$, Bandung Sahari ${ }^{2}$ \\ ${ }^{1}$ Department of Plant Protection, Faculty of Agriculture, IPB University, Dramaga, Bogor, West Java 16680, Indonesia \\ ${ }^{2}$ PT Astra Agro Lestari, Jakarta \\ ${ }^{3}$ Center for Transdisciplinlary and Sustainability, CTSS IPB University, Jalan Raya Pajajaran, Bogor, West Java 16153, \\ Indonesia \\ Corresponding author. Email: damayanti@apps.ipb.ac.id
}

\begin{abstract}
Non crop vegetation provides a microclimate, alternative host and food source (nectar) for Parasitic Hymenoptera community. Oil palm-cattle integration system may reduce understorey non crop vegetation and also affects community structure of parasitic Hymenoptera. The aim of this research is to study effects of cattle integration on non-crop vegetation and on diversity, abundance as well as species composition of Parasitic Hymenoptera community. Ecological sampling was carried out on six oil palm blocks consisting of three blocks with cattle grazing and three blocks without cattle grazing. Vegetation analyses were carried out at four different times, namely (1) before cattle grazing, (2) 30 days, (3) 60 days, and (4) 90 days after cattle grazing. Parasitic Hymenoptera were surveyed using sweeping net, yellow pan trap, and malaise trap. Vegetation analysis was carried out using the $2 \mathrm{~m} \times 2 \mathrm{~m}$ quadrant method in three areas of oil palm plantations, namely path between palms, frond pile (gawangan mati) and harvesting path (pasar pikul). In total 4273 individuals were collected belonging to 185 morphospecies, 24 families, and 9 superfamilies. The results of this study indicate changing structure of non-crop vegetation community due to grazing activity does not significantly affect parasitic Hymenoptera diversity, but increases abundance and affect species composition. The proportion of flowering herbs in oil palm plantations plays a key role in affecting the diversity of parasitic Hymenoptera.
\end{abstract}

Keywords: parasitic Hymenoptera, diversity, abundance, vegetation, oil palm

\section{INTRODUCTION}

The presence of Hymenopteran parasitoids in agroecosystem is strongly influenced by the availability of flowering plants that provide microclimate, alternative hosts, and nectar for adult parasitoids [1,2]. Rohrig et al. [1] states that understorey non crop vegetation can provide flower nectar which can increase the viability of the insect and its survival. Sahari [2] reported that the diversity of parasitoids in oil palm plantations is strongly influenced by the availability of understorey vegetation, especially flowering herbs.

In order to increase the value of oil palm plantations, integrated palm oil-cattle program has been implemented in several areas in Indonesia that brings many consequences to biological control in the field. Oil palmcattle integration program is expected to support national meat self-sufficiency program regulated under the decree from Minister of Agriculture (Permentan) No.105 of 2014 concerning the integration of oil palm plantations with cattle cultivation. Oil palm plantations can provide abundant sources of non-crop vegetation that can be used as food for cattle. At the same time, the palm-cattle integration system provides benefits, which saves labor up to $50 \%$ / ha /year, reduces weed control costs by $30-50 \%$, increases weight per palm length $6-30 \%$ and reduces the use of chemical fertilizers and improves soil fertility due to the addition of organic material from cattle dung [3].

Unfortunately, oil palm-cattle integration scheme may bring consequences on the decrease of understorey vegetation diversity which is capable of affecting the presence of natural enemies, i.e. parasitoids. Reduction of flowering non vegetation may result in the decreasing alternative sources of nutrition and hosts of parasitoids [2, 4]. However, effects of decreasing vegetation due to cattle grazing on parasitoid communities has never been done in Indonesia. Therefore, this research will concentrate on the evaluation of changing of the structure of non-crop vegetation as a result of palm-cattle integration on diversity, abundance, and species composition of the Hymenoptera parasitic community. 


\subsubsection{Study site}

Ecological samplings were made on six selected blocks of oil palm plantations, where three blocks with cattle grazing $(\mathrm{P})$ and other three blocks without cattle grazing (K) (Figure 1). Each block is \pm 30 ha in size with age of oil palm \pm 21 years. Cattle grazing is usually carried out every four months which can deplete almost all understorey vegetation. However, for this study, we selected three blocks without cattle grazing experience.

\subsubsection{Sampling period}

Insect samplings and vegetation analysis were carried out in four different times, namely (0) before grazing, (1) 30 days, (2) 60 days, and (3) 90 days after grazing (P) (Figure 2). Similar samplings were also conducted in blocks without grazing (K).
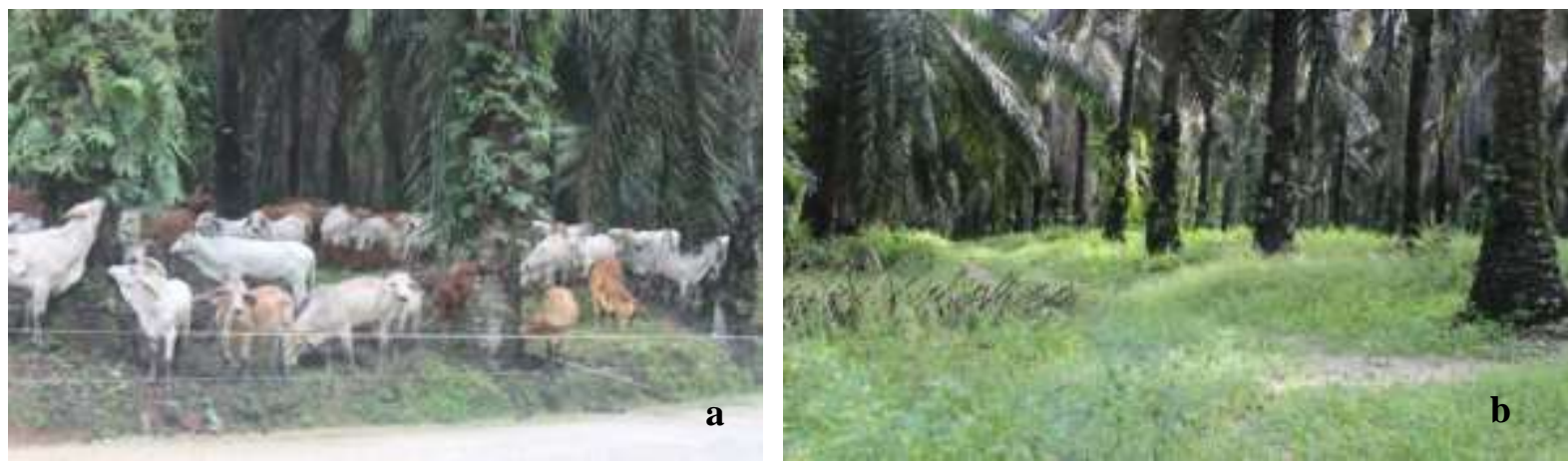

Figure 1 plantations with (a) cattle grazing and (b) without cattle grazing
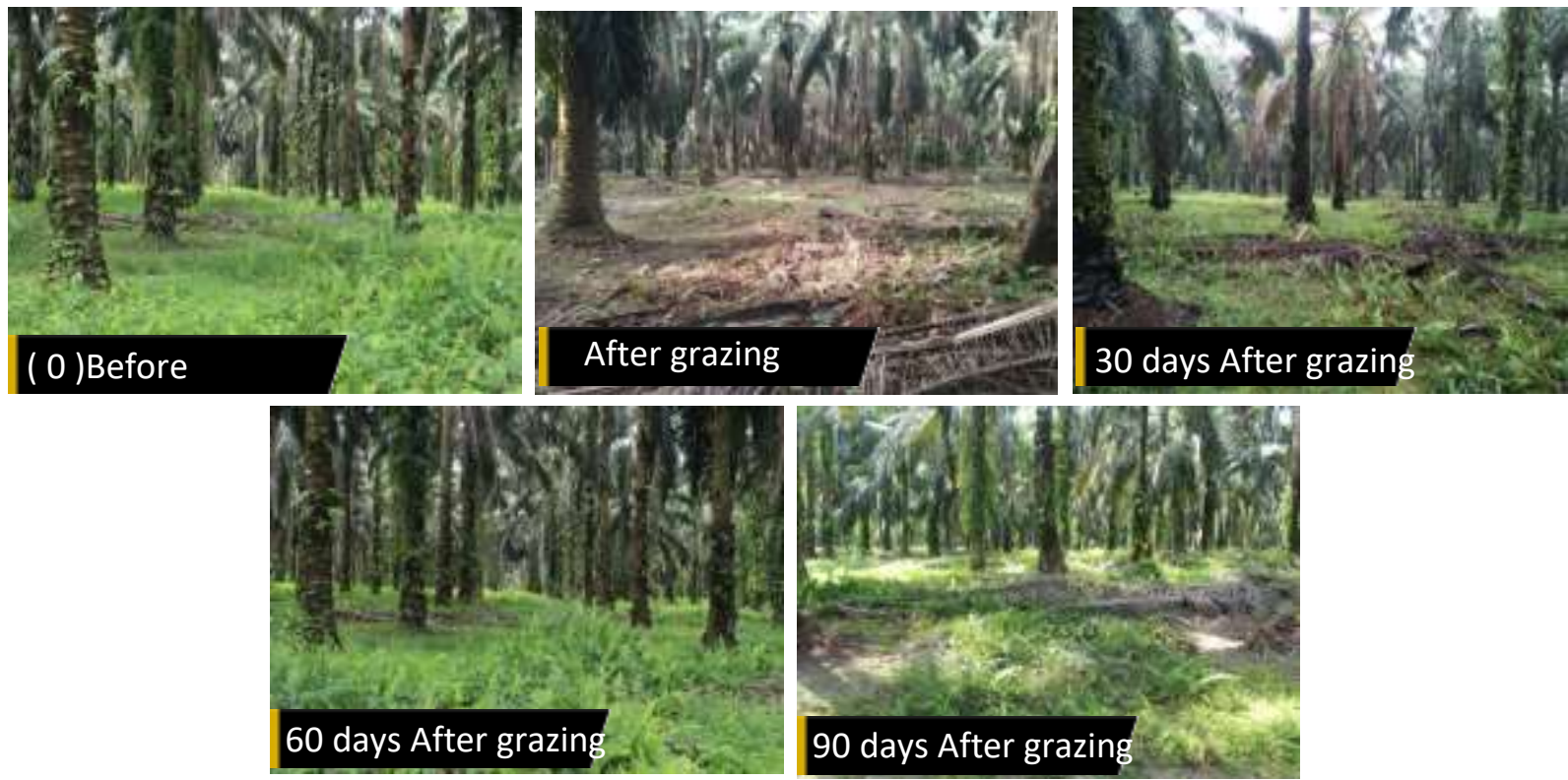

Figure 2 Land condition of oil palm-cattle integration at four different observation times 


\subsubsection{Insect sampling}

Insect sampling was carried out using three different trap methods, namely sweeping net, malaise trap and yellow pan trap. Each trap method used has its own function, including the sweeping net trap, which is the most effective method for collecting parasitic Hymenoptera [5]. Yellow pan trap traps are usually used to collect insects attracted to pollen (yellow), so they have a chance to get specific insects [6]. The target of the malaise trap is flying insects, especially for Hymenoptera and Diptera [7]. Sweeping net methods are carried out on five transect lines for each block. Samplings using the sweeping net method was carried out by swinging insect nets around the oil palm trees and understorey vegetation for 100 times in a double swing on each transect line. The yellow pan traps used in this study were 10 units which were placed for $2 \times 48$ hours on each observation block. Malaise traps with a height of $\pm 2 \mathrm{~m}$ were installed 1 unit in each block. Malaise traps were applied in the field for 72 hours.

\subsubsection{Vegetation analysis}

Understorey vegetation was observed in three plots, namely path between palms, frond pile (gawangan mati) and harvesting path (pasar pikul). Each plot was repeated for five times on each block. Vegetation observations were carried out by the quadrant method measuring $2 \times 2 \mathrm{~m}$. Each plot was observed for vegetation species and number of individuals of each vegetation species.

\subsubsection{Insect identification}

Collected specimens were identified using the Hymenoptera of the world identification manual: an identification guide to families [8].

\subsubsection{Data Analysis}

The results of the identification of parasitic Hymenoptera and vegetation were tabulated into a pivot table using Microsoft Excel 2010. Analysis of variance was applied to evaluate the difference among parameters. Bray- Curtis similarity index was used for analysis of beta diversity of parasitic Hymenoptera for observed units. Non Parametric Multidimensional Scaling (NMDS) ordination was used for the analysis of change of species composition. The diversity and abundance and composition of parasitic Hymenoptera were analysed using a statistical program version 3.1.1 $\mathrm{R}$ [9].

\subsection{Our Contribution}

This paper discusses effects of cattle integration on changes of non-crop vegetation and its impact on abundance, diversity and species composition of parasitic Hymenoptera community. Not all parasitic Hymenoptera species provide similar response to the loss of nonvegetation due to cattle grazing. This paper can also be used as a reference for biological control of pests attacking oil palm.

\subsection{Paper Structure}

The remainder of the paper is constructed as follows: the first section presents the effects of grazing on the diversity and abundance of Parasitic Hymenoptera, and the second section presents the relationship between understorey flowering vegetation and parasitic Hymenoptera community, the third presents the structure of parasitic Hymenoptera community, and the fourth concludes writing results

\section{RESULTS AND DISCUSSION}

\subsection{Effects of Cattle Grazing on Diversity and Abundance of Parasitic Hymenoptera}

In total 4273 individuals were obtained from 185 morphospecies, and 24 families of parasitic Hymenoptera (Table 1). Parasitic Hymenoptera obtained from plantations with grazing amounted to 2500 individuals consisting of 23 families and 169 species, while in the field without grazing there were 1773 individuals belonging to 24 families and 164 species of parasitic Hymenoptera. Cattle grazing does not affect the diversity of parasitic Hymenoptera, but significantly affect abundance of parasitic Hymenoptera (ANOVA: F1.22 = $4.92, \mathrm{P}=0.037)$. The results of this study indicate that not all species and / or families have the same response to disturbance caused by cattle grazing. Reduced vegetation has caused a decrease in number of species, but revegetation has returned species back to the plantations. The existence of understorey vegetation in oil palm plantations can be a source of nutrition, availability of alternative hosts, and shelter for parasitic Hymenoptera [2, 10]. However, different report [11] stated that grazing can increase the diversity of vegetation species in it. 
Table 1 Species diversity of parasitic Hymenoptera

\begin{tabular}{|c|c|c|c|}
\hline Observation time & Family & Species & Individual \\
\hline \multicolumn{4}{|c|}{ Without cattle grazing land } \\
\hline K0 & 17 & 91 & 384 \\
\hline K1 & 21 & 95 & 373 \\
\hline K2 & 20 & 108 & 534 \\
\hline K3 & 22 & 113 & 482 \\
\hline Sub total & 24 & 164 & 1773 \\
\hline Cattle grazing land & & & \\
\hline P0 & 20 & 101 & 492 \\
\hline P1 & 20 & 91 & 528 \\
\hline P2 & 21 & 108 & 699 \\
\hline P3 & 22 & 127 & 781 \\
\hline Sub total & 23 & 169 & 2500 \\
\hline Total & $\mathbf{2 4}$ & $\mathbf{1 8 5}$ & $\mathbf{4 2 7 3}$ \\
\hline
\end{tabular}

The code shows the area of study: the first letter $\mathrm{P}=$ Cattle grazing; observation time $\mathrm{P} 0=$ before grazing, $\mathrm{P} 1=30$ days after grazing, $\mathrm{P} 2=60$ days after grazing, $\mathrm{P} 3=90$ days after grazing; $\mathrm{K}$ $=$ Without cattle grazing; observation time $\mathrm{K} 0=0$ days, $\mathrm{K} 1=30$ days, $\mathrm{K} 2=60$ days, $\mathrm{K} 3=90$ days

\subsection{Relationship Between Flowering Vegetation Hymenoptera Community}

\section{and}

Species richness and abundance of parasitic Hymenoptera changed with changing proportion of flowering herbs but not with changes in vegetation density.
This situation occurs both in plantations with cattle grazing or without cattle grazing. On plantations with cattle grazing, although the number of vegetation species has not changed as in P2 and P3, the number of species and abundance of parasitic Hymenoptera continues to increase with the increasing proportion of flowering herbaceous plants (Figure 3, 4, and 5). In addition, on plantations without grazing, the number of species and abundance of parasitic Hymenoptera decreased as the proportion of flowering herbs decreased even though the number of species and density of vegetation increased.

The vegetation under the floor of observed oil palm plantations can be grouped into grasses, ferns, flowering herbs (standing and spreading), herbs, and moss. On plantations without cattle grazing, the vegetation structure in $\mathrm{K} 0$ to $\mathrm{K} 2$ was not found to be different. The proportion of flowering herbs tends to increase from $\mathrm{K} 0, \mathrm{~K} 1$ to $\mathrm{K} 2$ with $28 \%, 30 \%$, and $33 \%$ respectively. But in $\mathrm{K} 3$, the proportion of flowering herbs decreased to $18 \%$. However, at the same time, species number and density of understorey vegetation increased with increasing dominance of grass group (see Figure 3).

The proportion of flowering herbs on plantations with cattle grazing contributes less than $15 \%$ to the structure of non-crop vegetation. In the P0 observation (before grazing), the proportion of flowering herbs was only $14 \%$ and decreased dramatically in the P1 observation (30 days after grazing) to $8 \%$ followed by a decrease in density and number of species. The proportion of flowering herbs increased at P2 (60 days after grazing) and P3 (90 days after grazing) to $14 \%$ and $13 \%$ followed by an increase in the number of species and individual, although there was not much difference recorded between P2 and P3 (Figure $5)$.
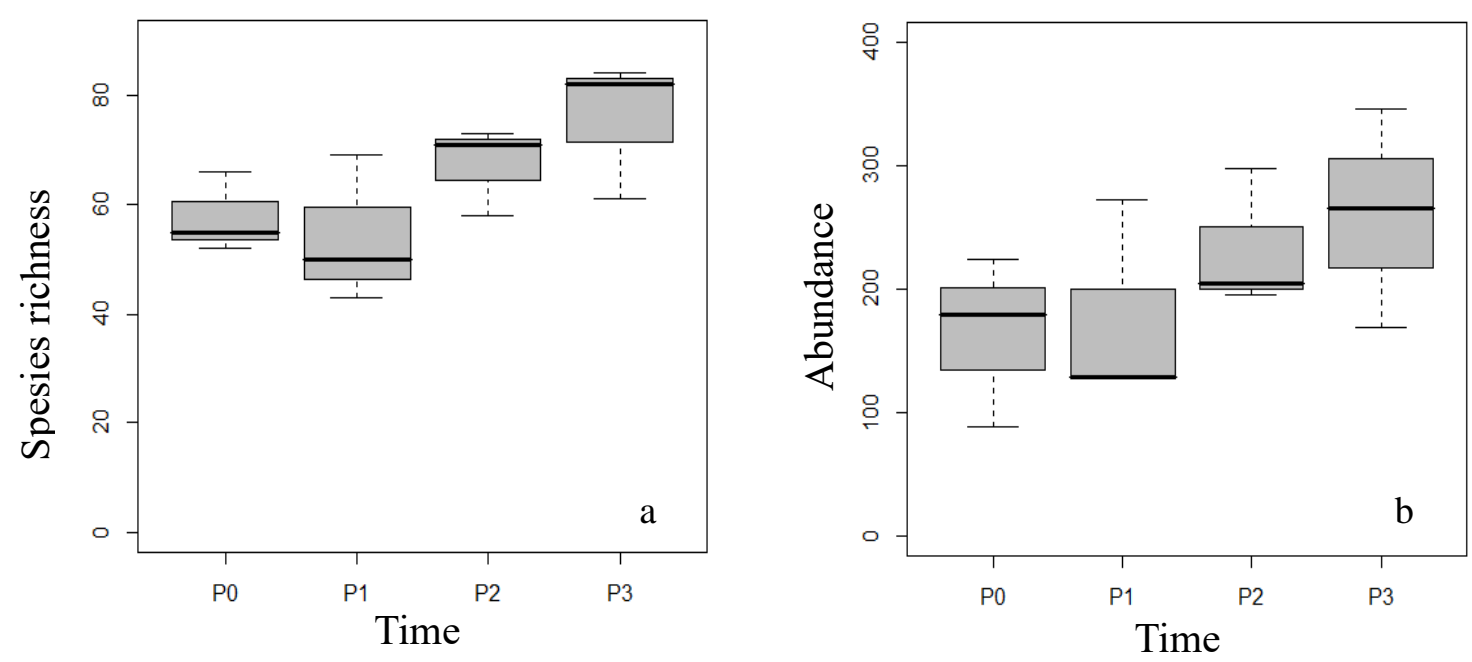

Figure 3 Boxplot of species richness and abundance of parasitic Hymenoptera at four different observational times in blocks with cattle grazing: (a) species richness $(\mathrm{F} 3.8=2.473 ; \mathrm{P}=0.136)$, (b) abundance $(\mathrm{F} 3.8=1.104 ; \mathrm{P}=$ 0.402) 

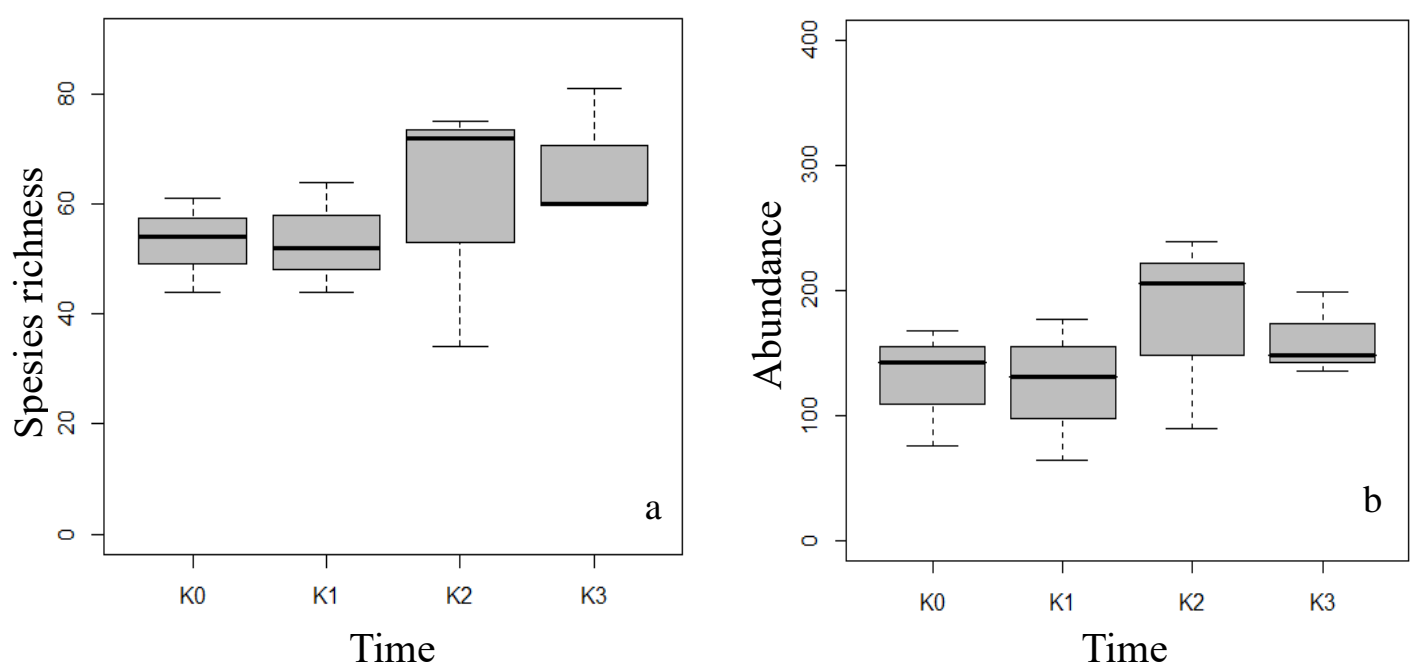

Figure 4 Boxplot of species richness and abundance of parasitic Hymenoptera at four different observation times in blocks without cattle grazing: (a) species richness $(\mathrm{F} 3.8=0.628 ; \mathrm{P}=0.617)$, (b) abundance $(\mathrm{F} 3.8=0.626 ; \mathrm{P}=0.618)$

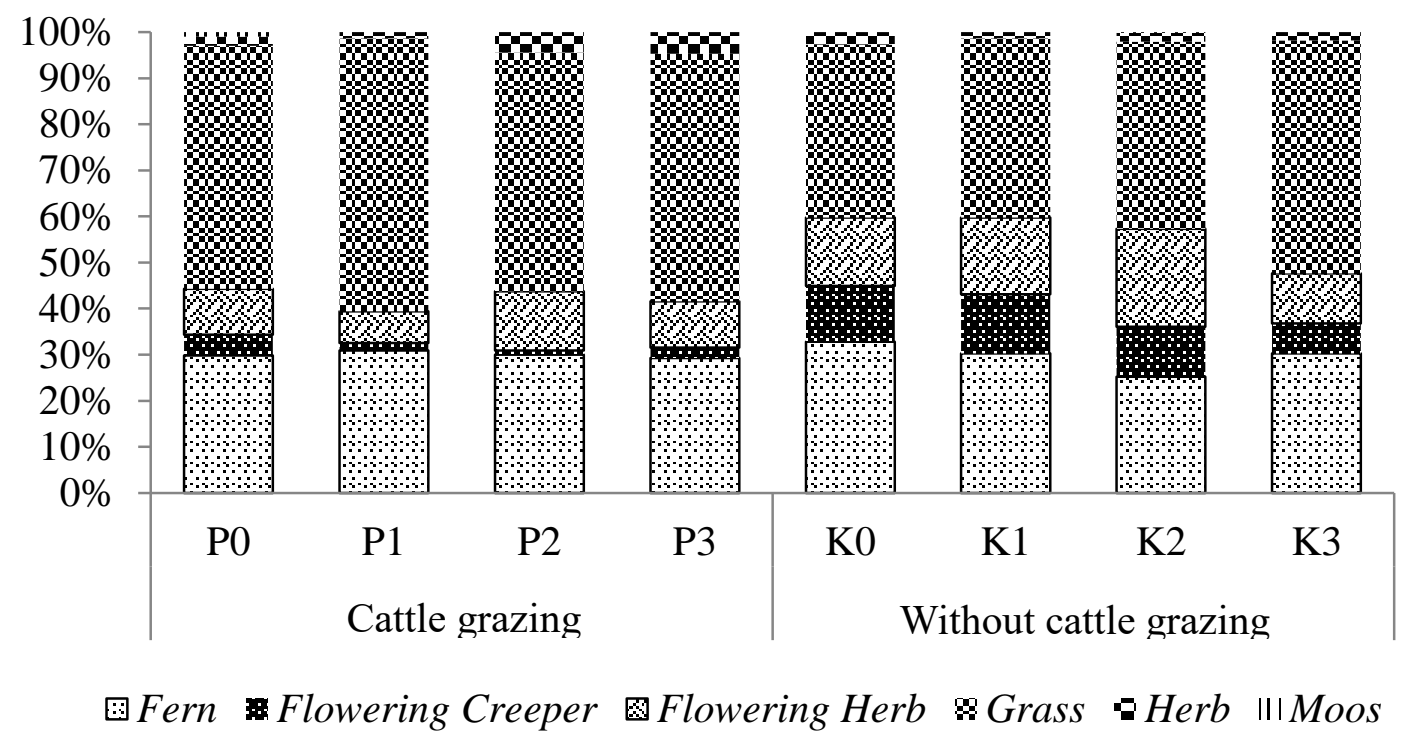

Figure 5 Graphs of proportions of vegetation abundance in each vegetation group at four time observations on blocks with cattle grazing and without cattle grazing $\mathrm{P}=$ cattle grazing; observation time $\mathrm{P} 0=$ before grazing, $\mathrm{P} 1=30$ days after grazing, $\mathrm{P} 2=60$ days after grazing, $\mathrm{P} 3=90$ days after grazing. $\mathrm{K}=$ No grazing; observation time $\mathrm{K} 0=0$ days, $\mathrm{K} 1$ $=30$ days, $\mathrm{K} 2=60$ days, $\mathrm{K} 3=90$ days

This study found that non crop vegetation community was composed by several groups of plants namely grasses, flowering herbs (standing and spreading) and mosses. In this study, disturbance of cattle grazing affected understorey vegetation. However, based on the results of this study, it can be seen that the structure of vegetation naturally changes from time to time so that it will affects insects that depend on certain vegetation groups, such as parasitoids. On plantations without cattle disturbance showed natural succession. The proportion of flowering herbs over 90 days decreased even though the number of species and overall density increased. The decrease in the proportion of flowering herbs was followed with increasing grass groups. In general, flowering herbaceous plants in oil palm plantations have a short lifespan of 2-5 months. The results of this study showed that on the $90^{\text {th }}$ day, the proportion of flowering herbs decreased dramatically from $33 \%$ (60 days) to $18 \%$ (90 days). This may relate to the cycle of flowering herbs. The process of vegetation succession naturally passes through sequential stages, thus forming a new vegetation complexity [12]. According to [13], grazing land, will undergo a continuous process of micro-regeneration of habitat, and can increase plant diversity because the dominating vegetation species 
decreases, so that it can affect competition between plants and have the opportunity to grow other vegetation species.

\subsection{Species Composition of Parasitic Hymenoptera Community}

The results of this study indicated that the structure of parasitic Hymenoptera community between plantations with cattle grazing $(\mathrm{P})$ and without cattle grazing $(\mathrm{K})$ showed a significant difference in ANOSIM based on the Bray-Curtis similarity index $(\mathrm{R}=0.259 ; \mathrm{P}=0.006)$ (Figure 6). NMDS ordination for K0, K1, K2, K3, P0 and $\mathrm{P} 1$ shows overlapping pattern, but not for $\mathrm{P} 2$ and $\mathrm{P} 3$. This indicated that species composition of parasitic Hymenoptera for P0 and P1 are linked to the K0 to K3, but not to $\mathrm{P} 2$ and $\mathrm{P} 3$. For $\mathrm{P} 2$ and $\mathrm{P} 3$, shows a narrower pattern than the others, this indicated that sampled locations for P2 and P3 have more similarity in species composition that reflects the similarity of supporting habitats.

Changes in vegetation during succession period seems to be followed by changes in species composition of parasitic Hymneoptera. In this study, proportion of flowering herbs affected the diversity of parasitic Hymenoptera. Richness of parasitic Hymenoptera in a habitat is influenced by the availability of hosts and food sources from existing vegetation [2]. The increase in density and species number of vegetation is not always followed by an increase in species and abundance of parasitic Hymenoptera. However, the increasing complexity of parasitic Hymenoptera is closely related to the decline or increase in the proportion of flowering herbs in ecosystem. This research also found that not all vegetation group plays role in maintaining the survival of
Hymenopteran parasitoids. Flowering vegetation was found to be a key group providing a nectar food source for parasitic Hymenoptera to survive. The presence of flowering plants such as Asystasia sp. is able to increase the presence of parasitic Hymnenoptera species [14] and can maintain parasitoid D. metesa, E. catoxanthae, Tetrachius sp. and Eurtoma sp. [15].

Two months after grazing, it is expected that structure of the new vegetation is stable enough to support parasitic Hymenoptera. In addition to host availability and competition in nature, the condition of the habitat around the observation plots can also influence the presence of parasitoids [16]. The response of parasitic Hymenoptera community to the loss of non- crop vegetation provides information on natural phenomena where the process of succession of vegetation goes hand in hand with the formation of species composition. Change in vegetation complexity, will be followed with changes in composition of species of associated organism, so that the presence of other insects such as predators, detritivores, and fungivores also changes with change in vegetation [17]. According to [14] the existence of flowering vegetation in a habitat can increase the wealth and abundance of Hymenopteran insects. Regeneration of vegetation in a post-grazing ecosystem, followed by the return of lost species such as important parasitoids that attack oil palm pests. In Oil palm plantations without cattle grazing, there is a dynamic of abundance and species richness between observed sites. This indicates that differences in insect diversity in a habitat is affected by the presence of plant factors, climatic conditions, and the condition of the surrounding habitat [18].

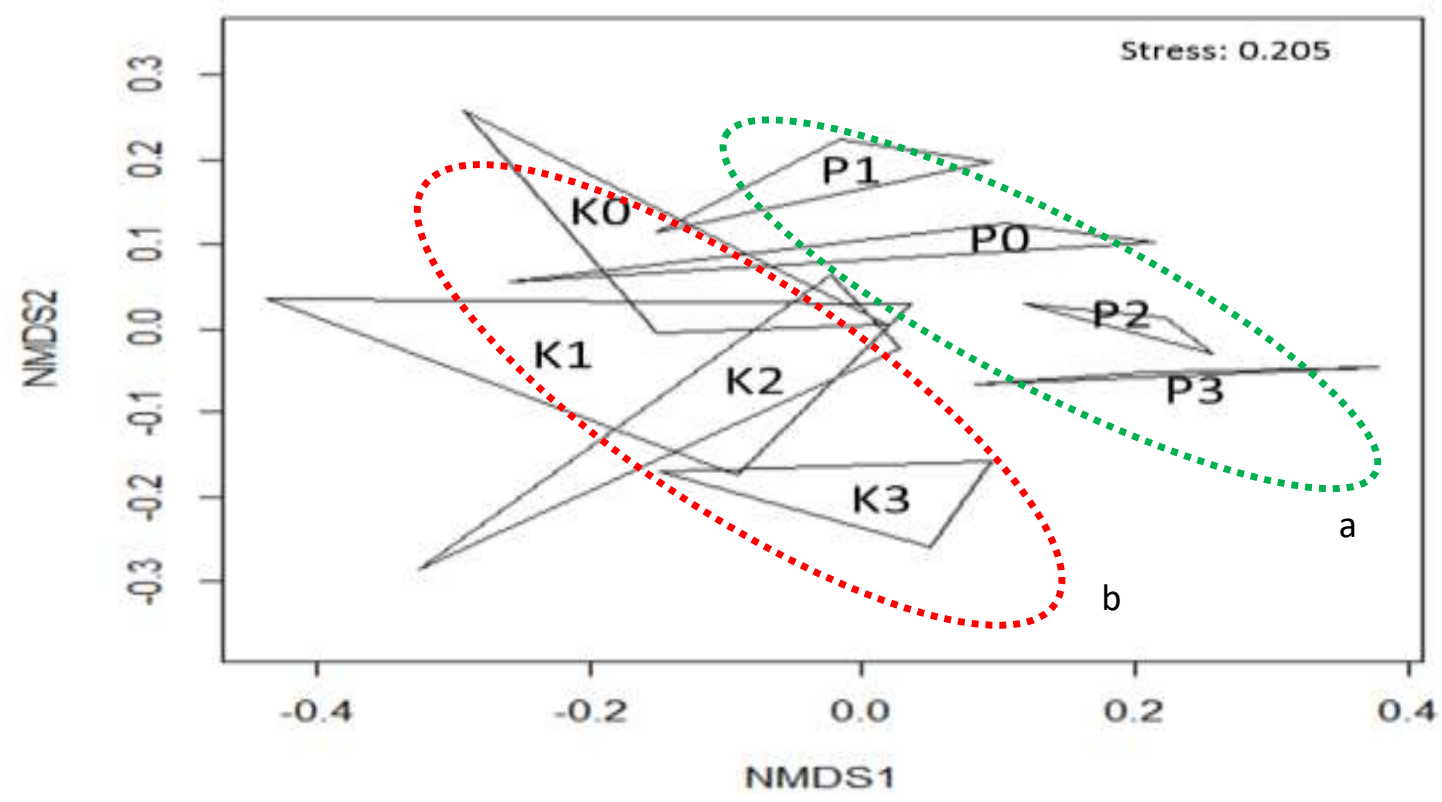

Figure 6 NMDS plot based on Bray-Curtis index to measure similarity of species composition of parasitic Hymenoptera between sampling sites. (a) Blocks with Cattle grazing P0 = before grazing, $\mathrm{P} 1=30$ days after grazing, $\mathrm{P} 2=60$ days after grazing, P3 $=90$ days after grazing, (b) blocks without cattle grazing; $\mathrm{K} 0=0$ days, $\mathrm{K} 1=30$ days, $\mathrm{K} 2=60$ days, $\mathrm{K} 3=90$ davs 
[7] J.A. Hutcheson, Malaise trap collection jar: a cheap simple modification, NZ Entomol. 14 (1991) 48-49

Change of non-crop vegetation in plantations with cattle grazing has no effect on diversity, but it affects abundance and species composition of parasitic Hymenoptera community. For plantations without cattle grazing, changes of understorey non crop vegetation has no effect on diversity, abundance and species composition of parasitic Hymenoptera community. Cattle grazing for every four months does not allow natural vegetation to fully return to its original state. The proportion of flowering herbs in the ecosystem plays a key role in affecting diversity of Hymenopteran parasitoids.

\section{ACKNOWLEDGMENT}

The author thanks PT. Astra Agro Lestari to fund this research. We sincerely thank Henny Hendarjanti dam Radhian Ardy Prabowo as field assistants and everyone at the Research and Development of PT. Astra Agro Lestari for its support during the research.

\section{REFERENCES}

[1] E. Rohrig, J. Silvinski, R. Wharton, Comparison of parasitic Hymenoptera capture in malaise traps baited with two flowering plants, Lobularia maritima (Brassicales: Brassicaceae) and Spermacoce verticillata (Gentianales: Rubiaceae). Florida Entomol. 91 (2008) 621-627

[2] B. Sahari, Hymenoptera parasitoid community structure in oil palm plantations, Pandu Senjaya Village, Pangkalan Lada District, Central Kalimantan, Dissertation, IPB University, 2012.

[3] Y. Adinata, D. Pamungkas, N.H. Krishna, Aryogi, Estimated population dynamics of beef cattle kept in the oil palm plantation area in South Kalimantan. J. Sains Dasar. 3(2) (2014)183-189

[4] E.T.S. Putra, A.F. Simatupang, S.W. Supriyanta, D. Indradewa, The growth of one-year old oil palm in tercropped with soybean and groundnut, J. Agric. Sci. 4(5) (2012) 169-180

[5] J.S. Noyes, A study of five methods of sampling Hymenoptera (Insecta) in a tropical rainforest with special reference to Parasitica, J. Nat. Hist. 23 (1989) 285-298

[6] M. Shweta, K. Rajmohana, A comparison of sweep net, yellow pan trap, and malaise trap for sampling parasitic Hymenoptera in a backyard habitat in Kerala, Entomology. 43(1) (2018) 33-44

[8] H. Goulet, J.T. Huber, Hymenoptera of the World: An Identification Guide to Families. Ontario (CA): Minister of Supply and Services, 1993.

[9] R Development Core Team, R: A Language and Environment for Statistical Computing. Vienna: R Foundation for Statistical Computing, 2012.

[10] I.L.I. Putra, Pudjianto, N. Maryana, Hymenoptera diversity of parasitoids in oil palm plantations of PTPN VIII Cindali, Bogor, J HPT Tropika. 16(2) (2016) 165-174

[11] Lugo SF, Nascimento LD, Mellado M, Arevalo JR, Grazing effect on species richness depends on scale: a 5-year study in Tenerife pastures (Canary Islands), Plant Ecol. 212 (3) (2010) 423-432. DOI $10.1007 / \mathrm{s} 11258-010-9834-6$

[12] H. Giourga, N.S. Margaris, Effects of grazing pressure on succession process and productivity of old fields on Mediterranean Islands, Environ. Manage. 22 (4) (1988) 589-596

[13] Y. Osem, A. Perevolotsky, J. Kigel, Site productivity and plant siza explain the response of annual spesies to grazing exclusion in a Mediterranean semi-arid rangeland, J. Ecol. 92 (2004) 297-309

[14] A. Azhar, The role of flowering plants and riparian areas on the diversity and composition of Hymenoptera parasitic species in forest, rubber and oil palm fields in Jambi. Master's Thesis, IPB University, 2019.

[15] M.W. Basri, S. Simon, S. Ravigadevi, A. Othman, Beneficial plant for the natural enemies of the bagworm in oil palm plantations. In: Arifin D, Chan KW, Sharifah SRSA, editor. Proceedings of the 1999 PORIM International Palm Oil CongressEmerging Technologies and Opportunities in the Next Millennium. Kuala Lumpur: Palm Oil Research Institute of Malaysia, 1999, pp. 441-445.

[16] J.M. Tylianakis, T. Tscharntke, O.T. Lewis, Habitat modification alters the structure of tropical host-parasitoid food webs, Nature. 445 (2007) 202-205

[17] G.A. Rahayu, Diversity and functional role of insects in the reclamation area in Berau, East Kalimantan. Master's Thesis, IPB University, 2016.

[18] A. Rizali, D. Buchori, H. Triwidodo, Insect diversity on forest rice fields: an indicator of environmental health. Biological. 9 (2) (2002) 4148 